LBL-37805 Rev.

\title{
MODELING PATTERNS OF HOT WATER USE IN HOUSEHOLDS
}

James D. Lutz, Xiaomin Liu, James E. McMahon, Camilla Dunham, Leslie J. Shown, Quandra T. McGrue

Energy Analysis Program

Energy and Environment Division

Ernest Orlando Lawrence Berkeley National Laboratory

Berkeley, California 94720

November 1996

This work was supported by the Assistant Secretary for Energy Efficiency and Renewable Energy, Office of Building Technologies, of the U.S. Department of Energy under Contract No. DE-AC03-76SF00098. 


\begin{abstract}
This report presents a detailed model of hot water use patterns in individual households. The model improves upon an existing model by including the effects of four conditions that were previously unaccounted for: the absence of a clothes washer; the absence of a dishwasher; a household consisting of seniors only; and a household that does not pay for its own hot water use. Although these four conditions can significantly affect residential hot water use, and have been noted in other studies, this is the first time that they have been incorporated into a detailed model. This model allows detailed evaluation of the impact of potential efficiency standards for water heaters and other market transformation policies.
\end{abstract}




\section{TABLE OF CONTENTS}

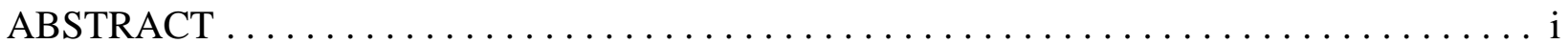

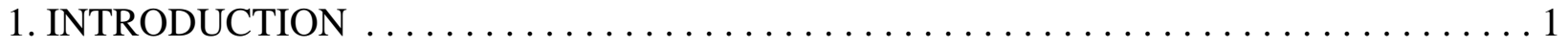

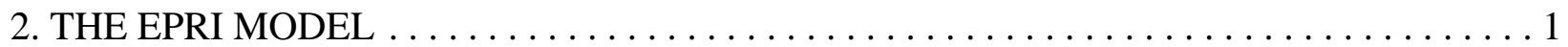

3. THE EXPANDED RESIDENTIAL HOT WATER USE MODEL $\ldots \ldots \ldots \ldots \ldots \ldots \ldots$.

No Clothes Washers . . . . . . . . . . . . . . . . . . . . . . . . . . . . . . . 7

No Dishwashers ...................................... 11

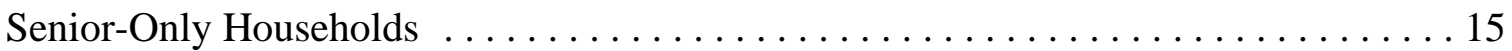

Households Not Paying for Hot Water $\ldots \ldots \ldots \ldots \ldots \ldots \ldots \ldots \ldots \ldots \ldots$

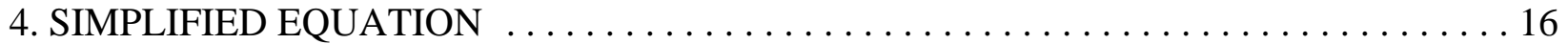

5. COMPARISON WITH OTHER STUDIES $\ldots \ldots \ldots \ldots \ldots \ldots \ldots \ldots \ldots \ldots \ldots \ldots \ldots \ldots \ldots$

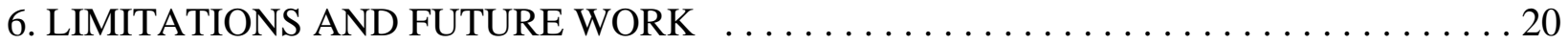

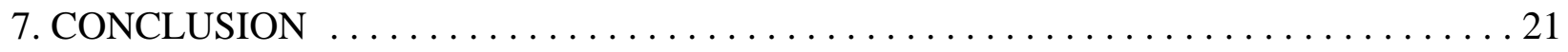

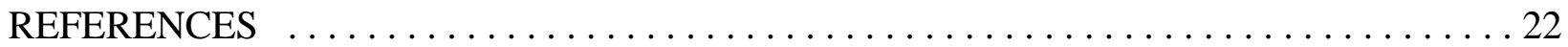

APPENDIX A: EXPANDED MODEL EQUATIONS $\ldots \ldots \ldots \ldots \ldots \ldots \ldots \ldots \ldots \ldots \ldots$ 


\section{INTRODUCTION}

The energy consumed by residential water heaters accounts for approximately $11 \%$ of electricity consumption and $24 \%$ of gas consumption in the residential sector in the U.S. (EIA 1997). To estimate the demand requirements on water heaters, electric utilities use hot water consumption models. Models that forecast hot water consumption can also be used to compare the energy savings associated with different types of water heaters.

In 1985, Gilbert and Associates developed a residential hot water consumption model for the Electric Power Research Institute (EPRI) (Ladd 1985). Because the EPRI model was designed specifically for assessing hot water consumption in households with particularly high hot water usage, its analytical usefulness is limited. For example, the sample upon which the model was based included only single-family homes that had both dishwashers and clothes washers. In fact, Gilbert and Associates' final report to EPRI states that the "sample was limited in size and did not contain sufficient variation to statistically support all explanatory variables that might influence hot water consumption" (Ladd 1985).

Researchers at the Lawrence Berkeley National Laboratory (LBNL) have expanded the EPRI model to predict hot water demand by time-of-day for a broader range of households. The expanded version of the model accounts for:

- households that do not own dishwashers;

- households that do not own clothes washers;

- senior-only households in multi-family buildings; and

- households that do not pay for hot water.

Several studies have shown these factors to have a strong impact on hot water usage. The LBNL model uses demographic data and other types of information that can be obtained from U.S. Census Bureau and Energy Information Administration (EIA) databases.

In this paper, we first provide a brief overview of the original EPRI model. The objective of the EPRI model is reviewed, along with the study sample and the important variables from the study. We then justify the addition of four variables to the model, develop the equations used to include the four variables, and explain the details of the expanded model. Finally, we discuss the limitations of the expanded model and make recommendations for future work.

\section{THE EPRI MODEL}

The goal of the EPRI project was to help utilities forecast electricity demand by predicting residential hot water consumption and thus the electricity use of water heaters. Water heaters have thermal storage capacities which make them ideal for load management strategies aimed at peak shaving and/or valley filling of daily electricity load profiles (Ladd 1985). The EPRI model could be used to help design and evaluate potential demand-side management programs that utilities could use to control electricity demand.

The EPRI model was developed by Gilbert and Associates for EPRI in 1985. The model is based on data collected before 1980 and can be used to estimate the amount of hot water, by time 
of day, consumed by individual households. To provide data for the model, data was gathered from a sample of 110 households. Each household was metered for hot water usage and water heater electricity consumption. Additional variables gathered for each household included: latitude, outside air temperature, inlet water temperature, water heater thermostat setting, demographic characteristics, housing structure, characteristics of the electric water heater, and a list of the major hot water consuming appliances in each household (Ladd 1985).

\subsection{Features of the EPRI Model}

The defining features of the EPRI model are as follows:

- Although many studies report only qualitative descriptions of hot water use patterns, the EPRI model is based upon statistical analysis procedures of model validation, variable selection, and error estimating.

- A set of multiple regression equations predicts the behavioral structure of hot water demands at different times of day, rather than simply predicting an average daily consumption rate.

- The model disaggregates demographic features into three age groups instead of using the typical household (i.e., a family composed of two adults and two children) or the total number of residents.

- Hot water demand is predicted as a function of three types of variables: demographic, climatic, and descriptions of water heaters.

\subsection{Sample Population for the EPRI Model}

The sample population for the EPRI model was drawn from electric utility customers. Eleven electric utility companies each chose ten residential test customers, for a total sample of 110 households. Utility employees composed $28 \%$ of the sample. Every household in the study owned both a clothes washer and dishwasher.

\subsection{The EPRI Model Variables and Equations}

The EPRI study determined which variables expressed significant correlation with the dependent variable, residential hot water consumption. Variables that had high correlation with other independent variables were not used. Sixteen variables were analyzed to find the optimal set of explanatory variables for the behavioral model.

Seven of the initial 16 independent variables were chosen to be explanatory variables. The decision to eliminate the other nine variables was based on information obtained from the correlation analysis. For example, geographical latitude shared too many characteristics with outside air temperature and was therefore eliminated. The final set of explanatory variables is:

a. the number of people within a household, divided into three age groups,

- infants and young children (through age five),

- children (ages six to 13), and

- adults (ages 14 and older);

b. outside air temperature;

c. inlet water temperature of the water heater; 
d. thermostat setting of the lower heating element of the water heater;

e. size of the tank;

f. a dummy variable for an unemployed household member; and

g. four dummy variables, one for each season.

Dummy variables indicate the presence or absence of a condition. The value of the dummy variable for an unemployed household member would equal one if one or more unemployed member of the household stayed home during the day and would equal zero for any other situation. Dummy values for each season are set equal one for the season in question while the other seasons' values are set to zero.

The EPRI model contains 16 equations. The equations predict average hot water use in gallons per hour for different times of day. Weekdays and weekend days are considered separately. Each day is divided into eight periods of unequal length by combining hours with similar average hot water consumption by time of day, type of day, and season. The length of each period ranges from two to seven hours. Combining hours reduced the total number of equations. The lowest average consumption period extends from 11:01 p.m. to 6:00 a.m. and is followed by the highest average consumption period, from 6:01- 8:00 a.m. (Ladd 1985). The eight time periods for average per capita hot water consumption on summer weekdays are shown in the bar graph below. 
Eight Daily Periods

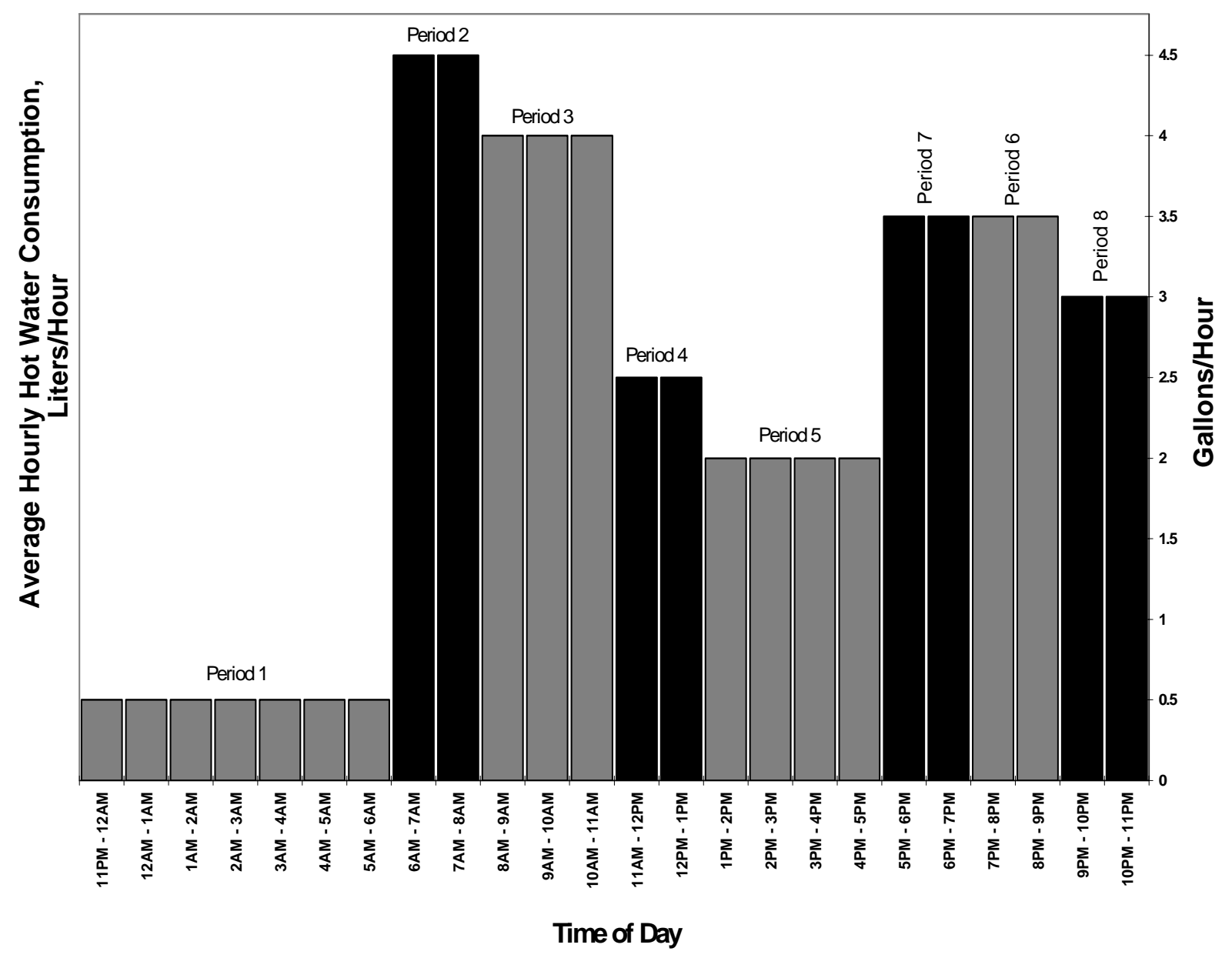

Figure 1. Average Hot Water Consumption for Summer Weekdays 


\subsection{Limitations of the EPRI Model}

Although the EPRI model represents a major improvement over previous work, the study has many limitations. The major drawback is the small sample size (only 110 households). In spite of the small sample size, however, this is the largest metered study of residential hot water use covering a wide range of regions in the United States that the authors are aware of.

This study covered only electric water heaters. No comparable study has been done on households with gas-fired water heaters. It is not known whether or how hot water use differs by type of water heater.

Each sample household owned a dishwasher and a clothes washer and paid for its own hot water. In addition, within the sample households, the model did not separately account for households occupied only by senior citizens. Indeed, the researchers of the EPRI study recognized the need for a broader sample for the behavioral model (Ladd 1985):

To produce results with the most global application the population should have been defined as all residential service customers in the continental United States using electrical storage hot water heaters as their primary source of domestic hot water. However, this population was reduced to the subset of households having both automatic dishwashers and clothes washers. This simplification complicates and reduces one's ability to extend the results of the study to the greater population of all households equipped with electric water heaters.

\section{THE EXPANDED RESIDENTIAL HOT WATER USE MODEL}

The EPRI study gave the research community a limited model for predicting hot water use on a household basis, and no studies since then have addressed the limitations of the model. To remedy some of the EPRI model's most significant limitations, we expanded the model to predict hot water consumption, by time-of-day, for a broader range of households. Although the studies from which we developed these corrections are based on various methods, samples, locations, and years, we believe that the significance of the corrections outweighs the inaccuracies created by inconsistencies among the studies. The limitations of our own analysis are described below in the Section 6.

\subsection{Justification of Four Additional Variables}

In this section, we present details of the four variables added to the model: households without clothes washers (no_cw), households without dishwashers (no_dw), households with senior citizen occupants only (senior), and households that do not pay for their hot water (no_pay).

The four additional variables adjust the predicted hot water use if the household does not have a dishwasher, does not have a clothes washer, has only seniors as occupants, or does not pay for hot water. Many studies suggest these conditions can have a significant impact on hot water use. Incorporating these four variables into the EPRI model allows for more accurate calculation of hot water consumption in a wider range of households. 


\subsubsection{No Clothes Washers}

Customers who own clothes washers use $19 \%$ of their annual supply of hot water to wash clothes (Ladd 1985). Correspondingly, in households without clothes washers, less hot water is used. Procter \& Gamble determined in 1988 that the absence of a clothes washer would reduce hot water usage by 28 liters (7.5 gallons) per day (Jacobsen 1989).

Although most U.S. households have clothes washers, approximately 20-25\% of households do not. Proctor \& Gamble reports that $19 \%$ of the U.S. population does not own clothes washers (Erikson 1995). In 1992, Appliance Magazine estimated the fraction of households with clothes washers at 74\% (Appliance 1994). Data from the Residential Energy Consumption Survey reports that $24 \%$ of households with their own water heater do not have clothes washers (EIA 1993).

\subsubsection{No Dishwashers}

Studies show that dishwashers use more hot water per load of dishes than an equivalent load washed by hand. In a 1990 study, a 22\% hot water difference was found in a laboratory setting between hand washing dishes and machine washing dishes: "5.1 gallons (19.3 liters) (per cycle) more were used if dishes were washed by machine than if they were washed by hand, all other things held constant" (Sanik 1990). Another study also showed more hot water use per load with dishwashers than by hand, but also pointed out that households with dishwashers wash fewer loads of dishes per week (Erikson 1995).

These differences are significant considering that approximately $45-55 \%$ of households in the U.S. do not own dishwashers. The EIA reports that, in 1993, only $45 \%$ of U.S. households had dishwashers (EIA 1995). Proctor \& Gamble estimates that only 55\% of U.S. households have dishwashers (Erikson 1995). Appliance Magazine estimated that 50\% of all households in 1992 did not own dishwashers (Appliance 1994).

\subsubsection{Senior-Only Households}

Currently, almost 18\% of U.S. households are senior-only households (EIA 1993). According to one study, the average household consumes 240 liters (63 gallons) of hot water daily, while senior-only households use only 90 liters (24 gallons) per day of hot water (Thrasher 1990). Expanding the behavioral model to account for this significant difference is important.

\subsubsection{No-Pay Households}

Several studies have reported that hot water consumption is above-average in households that do not pay for hot water. These households tend to be rental units, housing projects, or multi-family buildings with central water heating. Studies of rental households in the 1980s report an average hot water consumption of 320 liters (86 gallons) per day (Thrasher 1990). In a 1992 study performed for the New York State Energy Research and Development Authority, average daily consumption for rentals was 460 liters (124 gallons) per occupied apartment (Goldner 1994). Studies of public housing occupants show an average daily consumption of 280 liters (74 gallons) per household (Vine 1987). Approximately 3.1\% of U.S. households with individual water heaters 
do not pay for water heating (EIA 1993).

\subsection{Details of the Expanded Hot Water Use Model}

In this section, we describe the structure of the expanded model and provide values and equations for the four modifying factors. The details of the coefficients for the 16 equations are presented in matrix form in Appendix A.

\subsubsection{Expanded Model Structure}

The generic structure of the model is given below.

$$
\begin{aligned}
\text { Use }= & {\left[a_{0}+a_{1} \times \text { per }+a_{2} \times \text { age } 1+a_{3} \times \text { age } 2+a_{4} \times \text { age } 3\right.} \\
& +a_{5} \times \text { therm }+a_{6} \times \text { tank }+a_{7} \times \text { wtmp }+a_{8} \times \text { atmp }+a_{9} \times \text { athome } \\
& +a_{10} \times \text { spring }+a_{11} \times \text { summer }+a_{12} \times \text { fall }+a_{13} \times \text { winter } \\
& - \text { no_cw }- \text { no_dw }] \\
& \times \text { senior } \times \text { no_pay }
\end{aligned}
$$

The variables included in the equation are:

$$
\begin{aligned}
& \text { Use = hot water consumption, }(\mathrm{L} / \mathrm{hr}) \text {; } \\
& \text { per } \quad=\text { number of persons in household; } \\
& \text { age } 1=\text { number preschool children }(0-5 \mathrm{yrs}) \text {; } \\
& \text { age2 = number of school age children (6-13 yrs); } \\
& \text { age3 = number of adults (14 yrs and over); } \\
& \text { therm = water heater lower thermostat setting, }\left({ }^{\circ} \mathrm{C}\right) \text {; } \\
& \text { tank = water heater nominal tank size, }(\mathrm{L}) \text {; } \\
& \text { wtmp = water heater inlet water temperature, }\left({ }^{\circ} \mathrm{C}\right) \text {; } \\
& \text { atmp = outdoor air temperature, }\left({ }^{\circ} \mathrm{C}\right) \text {; } \\
& \text { athome }=\text { presence of adults at home during day; } \\
& \text { spring = dummy variable for Spring (1 if "spring", zero otherwise); } \\
& \text { summer = dummy variable for Summer (1 if "summer", zero otherwise); } \\
& \text { fall = dummy variable for Fall (1 if "fall”, zero otherwise); } \\
& \text { winter = dummy variable for Winter (1 if "winter", zero otherwise); } \\
& n o \_c w^{* *}=\text { a function indicating impact of not owning a clothes washer, }(\mathrm{L} / \mathrm{hr}) \text {; } \\
& n o \_d w^{* *}=\text { a function indicating impact of not owning a dishwasher, }(\mathrm{L} / \mathrm{hr}) \text {; } \\
& \text { senior** }^{* *} \text { a coefficient approximating effect of senior only households; and } \\
& \text { no_pay** }=\text { a coefficient approximating effect of occupants not paying for hot water. }
\end{aligned}
$$

(** Shows modifying terms added to the EPRI model for this analysis)

The model can be written conceptually as:

$$
F_{\text {Expanded }}(\ldots)=\left[F_{E P R I}(\ldots)-\text { no_cw }- \text { no_dw }\right] \times \text { senior } \times \text { no_pay }
$$

where $F_{E P R I}$ and $F_{\text {Expanded }}$ are the original and modified hot water consumption models, respectively. The dishwasher and clothes washer variables are subtracted only for certain time periods. The final sum for each time period is multiplied by the coefficients for senior-only and no-pay households. 


\subsubsection{Developing the Expanded Model}

The purpose of adding new variables is to correct the predicted hot water consumption from a model built with a restricted population and a biased sample. The coefficients of the new variables and the way they are incorporated into the model reflect the differences of hot water use between the general population and the specific subgroup.

\section{No Clothes Washers}

The amount of hot water used by a clothes washer depends on the number of loads laundered; the amount of water used in wash and rinse cycles; the fraction of hot wash, warm wash, and cold wash cycles; the fraction of warm rinse and cold rinse cycles; and the fraction of hot and cold water used to make warm water. The number of loads, the fraction of hot, warm, and cold washes; and the fraction of warm and cold rinses vary with family size. The expanded model accounts for these effects. Data from an extensive telephone survey by Proctor \& Gamble on clothes washing habits of 1522 households is used to estimate daily hot water use for clothes washing as a function of household size (Erikson 1995). This amount of hot water use is subtracted from the peak hot water use time periods if the household has no clothes washer. The time periods (evening peak from 7:01 - 9:00 p.m. on weekdays and late morning peak from 8:01 - 11:00 a.m. on weekends) are selected to avoid negative hot water flows.

The ratio of hot and cold water used in the warm wash and warm rinse cycles of clothes washers is determined from average wash water temperatures in clothes washers reported in the Proctor \& Gamble study. The warm water temperature is the average of the hot and cold water temperatures weighted by the amounts used. This can be written as:

$$
T_{\text {warm }}=T_{\text {hot }}(x)+T_{\text {cold }}(1-x)
$$

where:

$$
\begin{aligned}
& T_{\text {warm }}=\text { average warm water temperature, } 33.5^{\circ} \mathrm{C}\left(92.3^{\circ} \mathrm{F}\right) ; \\
& T_{\text {hot }}=\text { hot water temperature, } 48.9^{\circ} \mathrm{C}\left(120.1^{\circ} \mathrm{F}\right) ; \\
& T_{\text {cold }}=\text { reported cold water temperature, } 17.7^{\circ} \mathrm{C}\left(63.8^{\circ} \mathrm{F}\right) \text {; and } \\
& x=\text { fraction of total water that is hot. }
\end{aligned}
$$

Solving for $x$ gives 0.51 as the fraction of hot water used in warm water washes and rinses in clothes washers.

The amount of hot water used in each cycle is calculated as follows:

$$
\text { Use } e_{\text {cycle }}=V_{\text {cycle }} \times f_{\text {hot }}
$$

where:

$$
U_{s} e_{\text {cycle }}=\text { hot water use per cycle, (L/cycle); }
$$




$$
\begin{aligned}
& V_{\text {cycle }}=\text { total water use per cycle, (L/cycle); and } \\
& f_{\text {hot }}=\text { fraction of hot water use per cycle. }
\end{aligned}
$$

The total volumes of water used for the three cycles that use hot water (hot wash, warm wash, and warm rinse) are shown in Table 1 (Erickson 1995). These values are used to calculate hot water use per cycle.

\section{Table 1. Average Amount of Hot Water Used per Clothes Washer Cycle}

\begin{tabular}{lccc}
\hline Type of Cycle & $\begin{array}{c}\text { Total Volume of Water } \\
\left(V_{\text {cycle }}\right), \text { L (gallons) }\end{array}$ & $\begin{array}{c}\text { Fraction of Hot Water } \\
\left(f_{\text {hot }}\right)\end{array}$ & $\begin{array}{c}\text { Hot Water Use per Cycle } \\
\left(\text { Use }_{\text {cycle }}\right), \text { L (gallons) }\end{array}$ \\
\hline Hot wash & $77.2(20.4)$ & 1.0 & $77.2(20.4)$ \\
Warm wash & $77.2(20.4)$ & 0.51 & $39.0(10.3)$ \\
Warm rinse & $89.3(23.6)$ & 0.51 & $45.4(12.0)$ \\
\hline
\end{tabular}

Both the selection of hot water using cycles and the number of loads per week vary with the number of people per household. Hot water use for an average load can be calculated as the sum of the hot water used by each cycle multiplied by the frequency of hot water using cycles.

$$
\begin{aligned}
U s e_{\text {load }} & =\left(f_{\text {hot_wash }} \times U s e_{\text {hot_wash }}\right)+\left(f_{\text {warm_wash }} \times U s e_{\text {warm_wash }}\right) \\
& +\left(f_{\text {warm_rinse }} \times U s e_{\text {warm_rinse }}\right)
\end{aligned}
$$

where:

$U_{s e_{\text {load }}}=$ hot water use per average load, (L/load);

$f_{\text {hot_wash }}=$ frequency of hot wash cycles in all loads, (cycle/load);

Use $_{\text {hot_wash }}=$ hot water use per hot wash cycle, (L/cycle);

$f_{\text {warm_wash }}=$ frequency of warm wash cycles in all loads, (cycle/load);

$U_{s} e_{\text {warm_wash }}=$ hot water use per warm wash cycle, (L/cycle);

$f_{\text {warm_rinse }}=$ frequency of warm rinse cycles in all loads, (cycle/load); and

$U_{s} e_{\text {warm_rinse }}=$ hot water use per warm rinse cycle, (L/cycle).

The average frequencies of the three cycles that use hot water are shown in the following table by household size (Erickson 1995). These average frequencies, along with the amounts of hot water used in each cycle type (Table 1), are used to calculate average hot water use for laundry loads. The results are shown in Table 2. 
Table 2. Average Hot Water Use per Load

\begin{tabular}{cllll}
\hline Household Size (persons) & 1 & 2 & $3-4$ & $5+$ \\
\hline Cycle Frequency & & & & \\
$f_{\text {hot_wash }}$ & $17 \%$ & $15 \%$ & $16 \%$ & $16 \%$ \\
$f_{\text {warm_wash }}$ & $46 \%$ & $55 \%$ & $45 \%$ & $48 \%$ \\
$f_{\text {warm_rinse }}$ & $21 \%$ & $19 \%$ & $18 \%$ & $18 \%$ \\
\hline Use $_{\text {load }}$ L/load (gallons/load) & $40.5(10.7)$ & $41.6(11.0)$ & $38.2(10.1)$ & $39.4(10.4)$ \\
\hline
\end{tabular}

Combining hot water use per average load and average number of loads per week, average hot water use per day can be calculated as:

$$
\text { Use }_{\text {day }}=\frac{\left(\text { Loads }_{\text {week }} \times U s e_{\text {load }}\right)}{7}
$$

where:

$$
\begin{aligned}
& U_{s e_{\text {day }}}=\text { average hot water use per day, (L/day); } \\
& \text { Loads }_{\text {week }}=\text { average number of loads per week, (load/week); } \\
& \text { Use }_{\text {load }}=\text { hot water use per average load, (L/load); and } \\
& 7=\text { to convert from weeks to days, (days/week). }
\end{aligned}
$$

The reported average number of loads per week by household size and the calculated average hot water use per day are shown in Table 3 (Erickson 1995).

Table 3. Average Hot Water Use per Day in Clothes Washers

\begin{tabular}{lcccc}
\hline Household Size (persons) & 1 & 2 & $3-4$ & $5+$ \\
\hline Loads $_{\text {week }}$ & 3.85 & 5.97 & 8.73 & 12.00 \\
\hline $\begin{array}{l}\text { Use } \\
\text { (gallons/day) }\end{array}$ & $22.3(5.90)$ & $35.5(9.39)$ & $47.5(12.55)$ & $67.3(17.78)$ \\
\hline
\end{tabular}

The demographic data available from the Proctor \& Gamble study for households using clothes washers fall into four categories of household size: 1, 2, 3-4, and 5+. Based on 1990 Census data, the weighted-average household sizes for these four household-size categories are 1, 2, 3.46, and 5.51, respectively (Census 1991). The point of zero hot water use for an unoccupied household was added, assuming an empty house uses no hot water. This is not true for energy use. A water heater that is not providing hot water will still use energy to make up for standby losses. A least squares fit of average daily hot water use by weighted-average household size forced through the origin, using a combination of linear and square root terms, gives: 


$$
\begin{aligned}
U s e_{\text {day }} & =4.4242 \times p e r+18.070 \times \sqrt{p e r}-\text { L/day } \\
& =1.1688 \times p e r+4.7737 \times \sqrt{p e r}-g p d
\end{aligned}
$$

Both the calculated values and the equation of average daily hot water use for clothes washing are plotted in Figure 2.

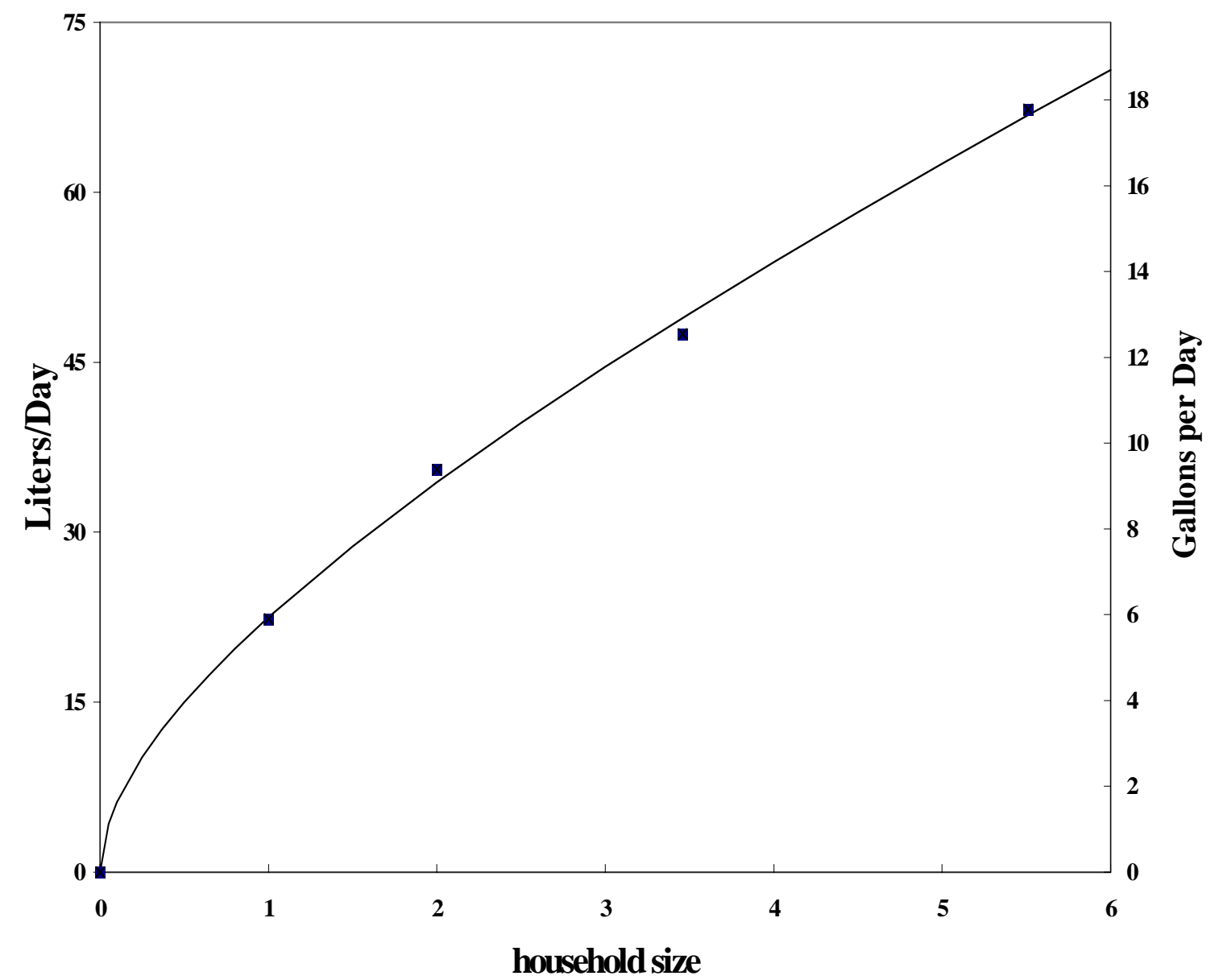

Figure 2 Hot Water Use in Clothes Washers

Equation (7) predicts average hot water use per day in clothes washers. The expanded model predicts average liters per hour for each time period. To be used in the expanded model, see Equation (1), this term must be divided by the number of hours included in the time period to which clothes washers are assigned. The final equation for the no_cw term used in the model is: 


$$
\begin{aligned}
& \left\{\begin{array}{cc}
\text { If Clothes Washer Present: } \\
0 & \text { (all hours) }
\end{array}\right. \\
& \text { If No Clothes Washer Present: } \\
& \text { no } c w= \\
& (L \overline{/ d} a y) \\
& \left.\frac{4.4242 \times p e r+18.070 \times \sqrt{p e r}}{2} \quad \text { (hour 7-9 pm weekdays }\right) \\
& \frac{4.4242 \times \text { per }+18.070 \times \sqrt{\text { per }}}{3} \quad(\text { hour 8-11 am weekends }) \\
& 0 \quad \text { (all other hours) }
\end{aligned}
$$

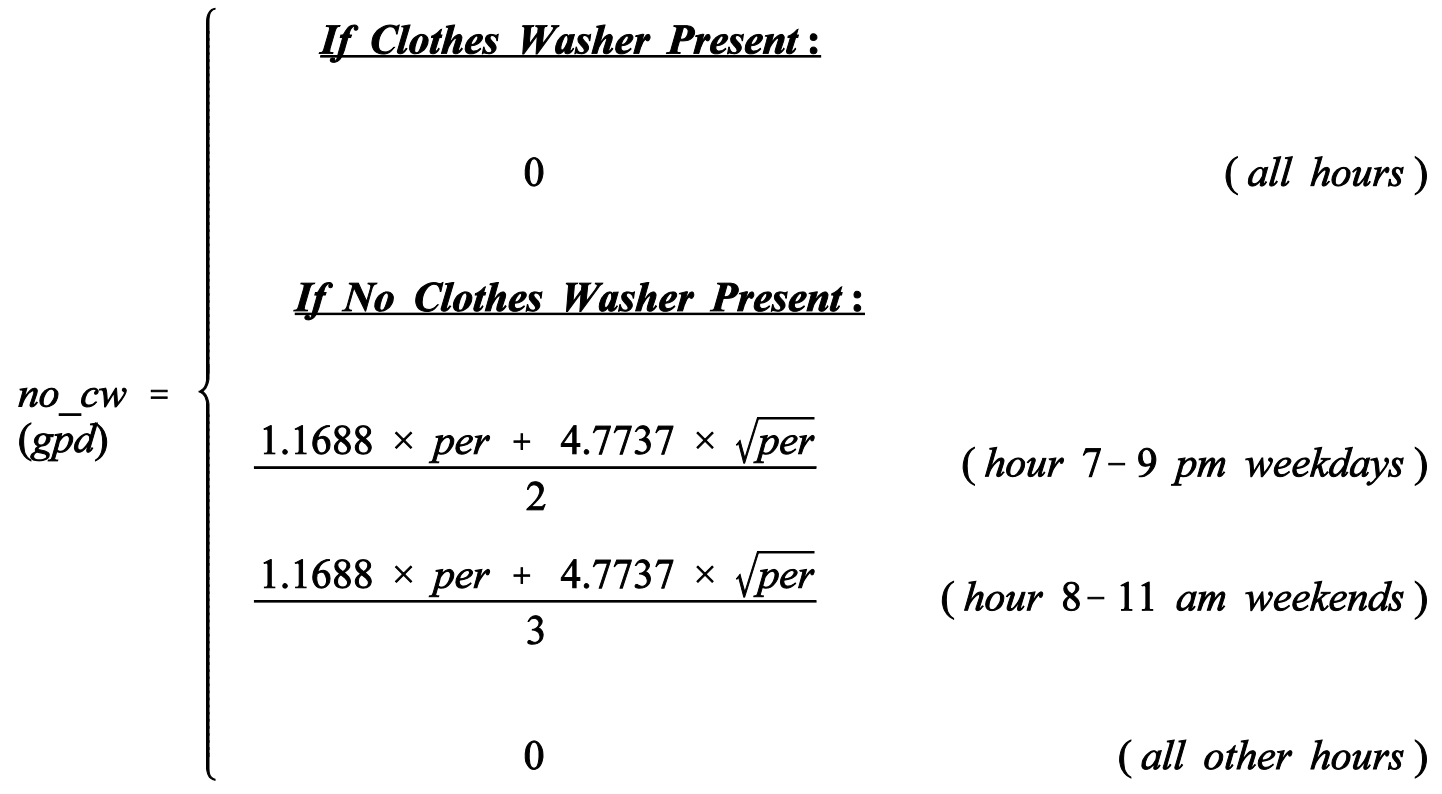

\section{No Dishwashers}

The expanded model also makes corrections for the absence of a dishwasher in a household. The number of loads washed by hand or by dishwasher varies with family size. As with clothes washer data, the dishwasher data was from Procter \& Gamble (Erikson 1995).

The fraction of hot water used for warm water in hand washing is determined from average temperatures in a similar manner as for clothes washers. The temperatures reported here are measured at the tap, and thus are different from those measured at the clothes washer. The warm 
water temperature is the average of the hot and cold tap water temperatures weighted by the amounts used. This can be written as:

$$
T_{\text {warm }}=T_{\text {hot }}(x)+T_{\text {cold }}(1-x)
$$

where:

$$
\begin{aligned}
& T_{\text {warm }}=\text { warm water temperature, } 46.1^{\circ} \mathrm{C}\left(115.0^{\circ} \mathrm{F}\right) ; \\
& T_{\text {hot }}=\text { hot water temperature, } 54.0^{\circ} \mathrm{C}\left(129.2^{\circ} \mathrm{F}\right) ; \\
& T_{\text {cold }}=\text { cold water temperature, } 15.9^{\circ} \mathrm{C}\left(60.6^{\circ} \mathrm{F}\right) ; \\
& x=\text { fraction of total water that is hot. }
\end{aligned}
$$

Solving for $x$ gives 0.79 as the fraction of hot water used for hand washing dishes.

For both dishwashers and hand washing dishes the average daily hot water use is calculated as:

$$
U s e_{\text {day }}=\frac{\left(\text { Loads }_{\text {week }} \times U s e_{\text {load }} \times f_{\text {hot }}\right)}{7}
$$

where:

$$
\begin{aligned}
& \text { Use }_{\text {day }}=\text { average hot water use per day, (L/day); } \\
& \text { Loads }_{\text {week }}=\text { average number of loads per week, (load/week); } \\
& \text { Use }_{\text {load }}=\text { average water use per load, (L/load); } \\
& f_{\text {hot }}=\text { fraction of water use per load that is hot; and } \\
& 7=\text { to convert from weeks to days, (days/week). }
\end{aligned}
$$

Using data from the Proctor and Gamble report for households of different sizes, average daily hot water use for dishwashers and hand washing dishes is presented in Tables 4 and 5, respectively. 
Table 4. Average Daily Hot Water Use for Dishwashers

\begin{tabular}{lcccc}
\hline $\begin{array}{l}\text { Household Size } \\
\text { (persons) }\end{array}$ & 1 & 2 & $3-4$ & $5+$ \\
\hline Loads $_{\text {week }}$ & 2.97 & 4.11 & 4.75 & 6.64 \\
Use $_{\text {load }}$ L (gallons) & $40.69(10.75)$ & $40.69(10.75)$ & $40.69(10.75)$ & $40.69(10.75)$ \\
$f_{\text {hot }}$ & 1.0 & 1.0 & 1.0 & 1.0 \\
\hline$U_{\text {Use }}$ day L (gallons) & $17.3(4.56)$ & $23.9(6.31)$ & $27.6(7.29)$ & $38.6(10.20)$ \\
\hline
\end{tabular}

Table 5. Average Daily Hot Water Use for Hand Washing Dishes

\begin{tabular}{lcccc}
\hline $\begin{array}{l}\text { Household Size } \\
\text { (persons) }\end{array}$ & 1 & 2 & $3-4$ & $5+$ \\
\hline Loads $_{\text {week }}$ & 9.18 & 9.57 & 10.00 & 11.00 \\
Use $_{\text {load }}$ L (gallons) & $9.5(2.5)$ & $9.5(2.5)$ & $9.5(2.5)$ & $9.5(2.5)$ \\
$f_{\text {hot }}$ & 0.79 & 0.79 & 0.79 & 0.79 \\
\hline Use $_{\text {day }}$ L (gallons) & $9.80(2.59)$ & $10.22(2.70)$ & $10.67(2.82)$ & $11.73(3.10)$ \\
\hline
\end{tabular}

The table below sums the average daily hot water consumption for dishwashers and hand washing dishes. Hot water savings are also calculated. The weighted household sizes are the same as for clothes washers.

Table 6. Average Daily Hot Water Savings for Hand Washing Dishes

\begin{tabular}{lllll}
\hline $\begin{array}{l}\text { Household Size } \\
\text { (persons) }\end{array}$ & 1 & 2 & 3.46 & 5.51 \\
\hline $\begin{array}{l}\text { Dishwasher } \\
\text { L (gallons) }\end{array}$ & $17.3(4.56)$ & $23.9(6.31)$ & $27.6(7.29)$ & $38.6(10.20)$ \\
$\begin{array}{l}\text { Hand Washing } \\
\text { L (gallons) }\end{array}$ & $9.80(2.59)$ & $10.22(2.70)$ & $10.67(2.82)$ & $11.73(3.10)$ \\
\hline $\begin{array}{l}\text { Savings } \\
\text { L (gallons) }\end{array}$ & $7.46(1.97)$ & $13.7(3.61)$ & $16.9(4.47)$ & $26.9(7.10)$ \\
\hline
\end{tabular}

A least squares fit of average daily hot water savings for hand washing dishes compared to using dishwashers by weighted-average household size forced through the origin using a combination of linear and square root terms gives: 


$$
\begin{array}{rll}
U_{s e_{\text {day }}} & =2.620 \times p e r+5.054 \times \sqrt{p e r} & (\text { L/day }) \\
& =0.6920 \times p e r+1.3350 \times \sqrt{p e r} \quad(g p d)
\end{array}
$$

Both the calculated values and the equation of average daily hot water use for dishwashers are plotted in Figure 3. The values plotted show the incremental increase in hot water use for washing dishes using a dishwasher compared to hand washing dishes.

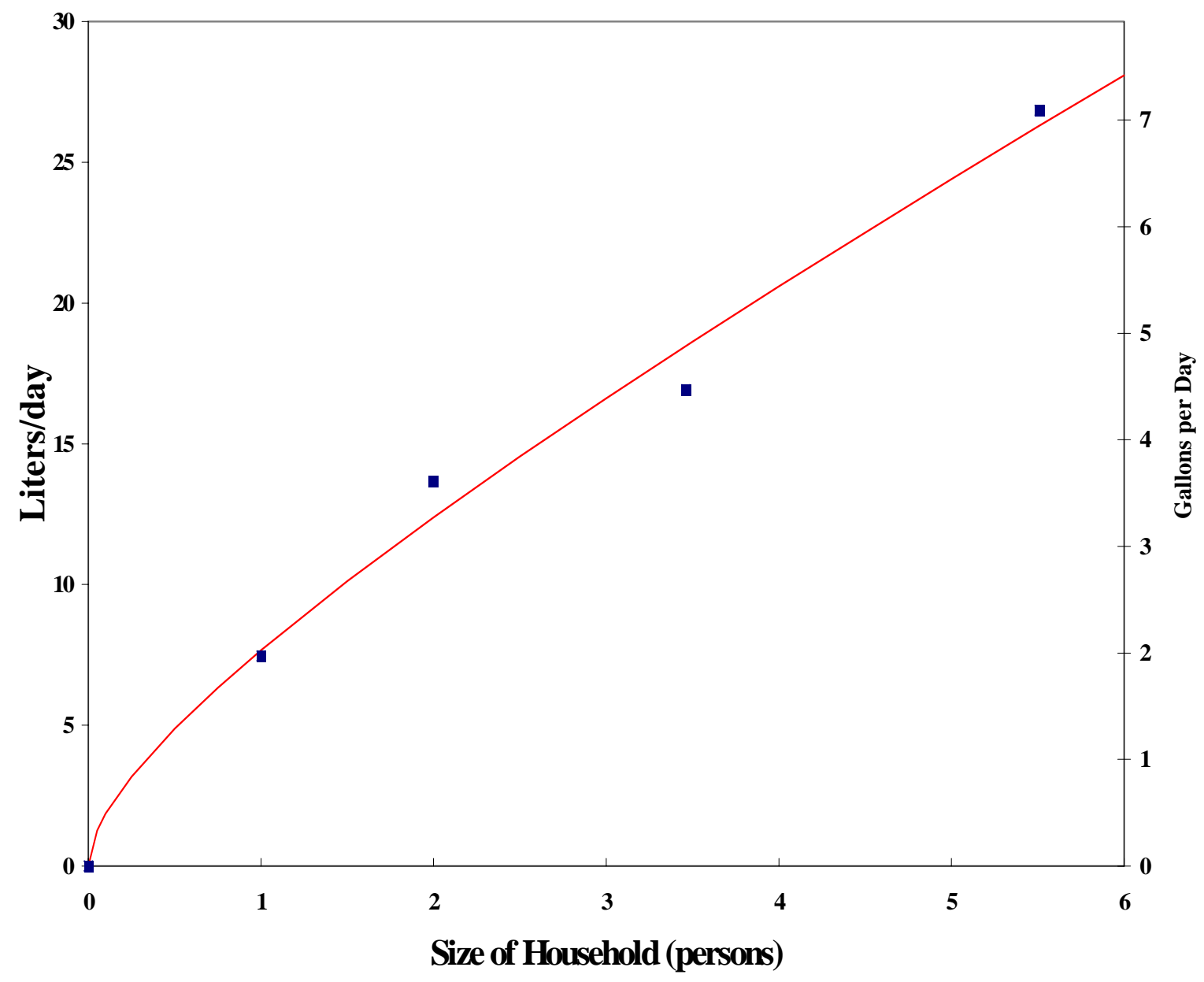

Figure 3 Hot Water Savings for Hand Washing Dishes Compared to Dishwasher Use

To avoid negative values of predicted hot water use, the savings resulting from the absence of a dishwasher are placed in the draw schedules only when peak hours occur. Thus, the modifier for the absence of a dishwasher is applied to the evening peak hours (5-9 pm) for both weekdays and weekends.

This equation predicts the average daily hot water savings for households that do not have a dishwasher. The expanded model reports average liters per hour for each time period. This equation must be divided by four, the number of hours in the 5:01 - 9:00 p.m. time period. The final equation for the term used in the model is: 


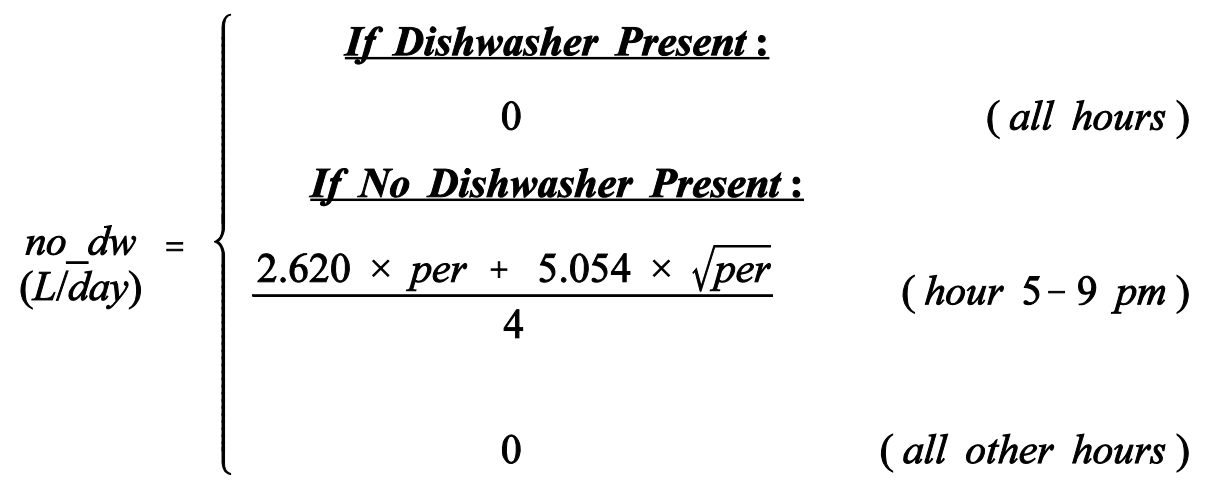

$$
\begin{array}{cc}
\text { If Dishwasher Present: } \\
0 \\
(g p d) \\
\text { If No Dishwasher Present: } \\
\frac{0.6920 \times p e r+1.3350 \times \sqrt{p e r}}{4} & \text { ( all hours) } \\
0 & \text { ( hour } 5-9 \mathrm{pm})
\end{array}
$$

\section{$\underline{\text { Senior-Only Households }}$}

The correction for a household in a multi-family building occupied only by seniors is accomplished by scaling down the hot water draw rates for all hours equally. The one study that focused on senior only households, was done on multi-family buildings. The scaling factor is the ratio of the average liters per day for senior-only households to the average liters per day for all households in the entire population (Thrasher 1990):

$$
F_{\text {senior }}=\frac{U s e_{\text {day_senior }}}{U s e_{\text {day_all }}}
$$

where:

$$
\begin{aligned}
& U s e_{\text {day_senior }}=\text { average hot water use per day for senior-only households, } \\
& \text { 90.1 L/day (23.8 gal/day); } \\
& U s e_{\text {day_all }}=\text { average hot water use per day for all households, } \\
& \text { 237.7 L/day (62.79 gal/day); and } \\
& F_{\text {senior }}=\text { scaling factor for senior-only households, (0.3790). }
\end{aligned}
$$

The final equation for the term used in the model to correct for senior-only households is: 


$$
\text { senior }=\left\{\begin{array}{lr}
0.3790 & \text { senior }- \text { only households } \\
1 & \text { all other households }
\end{array}\right.
$$

Households Not Paying for Hot Water

The correction for a household that does not pay for hot water is accomplished by scaling up the hot water draw rates for all hours equally. The scaling factor is the ratio of the average liters per day for households that do not pay for hot water to the average liters per day for all households in the entire population (Thrasher 1990):

$$
F_{\text {no_pay }}=\frac{U s e_{d a y \_n o \_p a y}}{U s e_{\text {day_all }}}
$$

where:

$$
\begin{aligned}
& U_{\text {say_no_pay }}=\text { average hot water use per day in households not paying for hot water, } \\
& \text { 323.8 L/day (85.55 gal/day); } \\
& \text { Use }_{\text {day_all }}=\text { average hot water use per day for all households, } \\
& \text { 237.7 L/day (62.79 gal/day); and } \\
& F_{\text {no_pay }}=\text { scaling factor for households that do not pay for hot water, (1.3625). }
\end{aligned}
$$

The final equation for the term used in the model to correct for not paying for hot water is:

$$
\text { no_pay }=\left\{\begin{array}{lr}
1.3625 & \text { for households that do not pay } \\
1 & \text { for households that do pay }
\end{array}\right.
$$

\section{SIMPLIFIED EQUATION}

For many situations, hourly-use patterns are not necessary and average daily hot water use is sufficient. A single equation for average daily hot water use throughout the year can be derived by summing the coefficients for all the terms in the detailed model equation. This simplified equation has the same general form as the detailed model shown in Equation (3). The coefficients have been weighted by the number of hours and number of days each term is used in a full year. The variables have the same meaning as in Equation (3). 


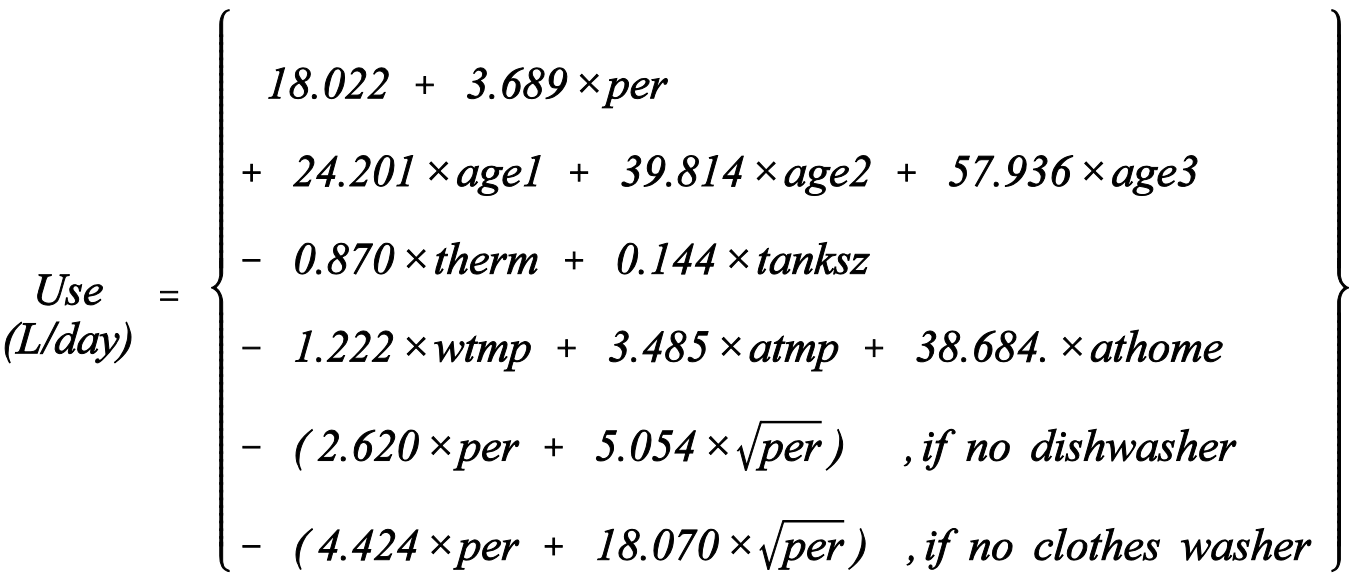

$$
\begin{aligned}
& \times\left\{\begin{array}{ll}
0.3790 & \text {, if senior only } \\
1.0 & \text {, if not senior only }
\end{array}\right\} \\
& \times\left\{\begin{array}{ll}
1.3625 & \text {, if no pay } \\
1.0 & \text {, if pay }
\end{array}\right\}
\end{aligned}
$$

$$
\begin{aligned}
& \begin{array}{l}
\text { Use } \\
(\text { gpd })
\end{array}=\left\{\begin{array}{l}
-1.78+0.9744 \times \text { per } \\
+6.3933 \times \text { age } 1+10.5178 \times \text { age }+15.3052 \times \text { age } 3 \\
-0.1277 \times \text { therm }+0.1437 \times \text { tanksz } \\
-0.1794 \times w \text { tmp }+0.5115 \times \text { atmp }+10.2191 \times \text { athome } \\
-(0.6920 \times \text { per }+1.3350 \times \sqrt{\text { per }}) \text {, if no dishwasher } \\
-(1.1688 \times \text { per }+4.7737 \times \sqrt{\text { per }}) \text {, if no clothes washer }
\end{array}\right\} \\
& \times\left\{\begin{array}{ll}
0.3790 & \text {, if senior only } \\
1.0 & \text {, if not senior only }
\end{array}\right\} \\
& \times\left\{\begin{array}{ll}
1.3625 & \text {, if no pay } \\
1.0 & \text {, if pay }
\end{array}\right\}
\end{aligned}
$$

\section{COMPARISON WITH OTHER STUDIES}

To evaluate the expanded model, we compared the average daily hot water consumption predicted by the simplified version of the model to the average daily hot water use reported in two 
studies of similar households. A rigorous verification was not possible because complete information at the household level is unavailable. For each comparison, the simplified model is applied to similar-sized households with reasonable estimates of age distribution and appliance ownership. Average air and water temperatures for the region of each study are used in the simplified model. Tables 7-10 show the results of these comparisons. Based on the data in Tables 7-10, we see that the simplified model produces values similar to the values obtained in other studies.

\section{Table 7. Typical Household in Toronto Area}

\begin{tabular}{ccl}
\hline $\begin{array}{c}\text { Daily Hot Water Use } \\
\text { L (gallons) }\end{array}$ & $\begin{array}{c}\text { Number of } \\
\text { People }\end{array}$ & Data Source and Comments \\
\hline $239(63.1)$ & 4 & $\begin{array}{l}\text { Source: Perlman et al. 1985 } \\
\text { estimated use for two adults, two children, dishwasher } \\
\text { and clothes washer }\end{array}$ \\
$268(70.8)$ & 4 & $\begin{array}{l}\text { Source: Simplified Equation } \\
\text { two adults, one at home, two school age children }\end{array}$ \\
$229(60.5)$ & 4 & $\begin{array}{l}\text { Source: Simplified Equation } \\
\text { two adults, none at home, two school age children }\end{array}$ \\
\hline
\end{tabular}

Table 8. Average Household in Florida Area

\begin{tabular}{ccl}
\hline $\begin{array}{c}\text { Daily Hot Water Use } \\
\text { L (gallons) }\end{array}$ & $\begin{array}{c}\text { Number of } \\
\text { People }\end{array}$ & Data Source and Comments \\
\hline $256(67.7)$ & 4 & $\begin{array}{l}\text { Source: Merrigan } 1988 \\
\text { average of } 25 \text { households, no other information given }\end{array}$ \\
$283(74.7)$ & 4 & $\begin{array}{l}\text { Source: Simplified Equation } \\
\text { one adult at home, clothes washer and dishwasher } \\
\text { one preschool child and one school age child }\end{array}$ \\
$245(64.7)$ & 4 & $\begin{array}{l}\text { Source: Simplified Equation } \\
\text { no adults at home, clothes washer and dishwasher } \\
\text { one preschool child and one school age child }\end{array}$ \\
\hline
\end{tabular}


Table 9. Senior-Only Households in Toronto Area

\begin{tabular}{ccl}
\hline $\begin{array}{c}\text { Daily Hot Water Use } \\
\text { L (gallons) }\end{array}$ & $\begin{array}{c}\text { Number of } \\
\text { People }\end{array}$ & Data Source and Comments \\
\hline $67.8(17.9)$ & 1.18 & $\begin{array}{l}\text { Source: Ciz 1986 and Milligan 1987 } \\
\text { one apartment building, 196 suites }\end{array}$ \\
$50.0(13.2)$ & 1 & $\begin{array}{l}\text { Source: Simplified Equation } \\
\text { adult at home, dishwasher, no clothes washer, do not } \\
\text { pay for hot water } \\
75.7(20.0)\end{array}$ \\
& 2 & $\begin{array}{l}\text { Source: Simplified Equation } \\
\text { both adults at home, dishwasher, no clothes washer, do } \\
\text { not pay for hot water }\end{array}$ \\
\hline
\end{tabular}

Table 10. Rental Households in Toronto Area

\begin{tabular}{ccl}
\hline $\begin{array}{c}\text { Daily Hot Water Use } \\
\text { L (gallons) }\end{array}$ & $\begin{array}{c}\text { Number of } \\
\text { People }\end{array}$ & Data Source and Comments \\
\hline 396 (104.7) & 4.36 & $\begin{array}{l}\text { Source: Ciz 1986 and Milligan 1987 } \\
\text { one apartment building, 196 suites }\end{array}$ \\
291 (77.0) & 4 & $\begin{array}{l}\text { Source: Simplified Equation } \\
\text { two school age children, adult at home, dishwasher, no } \\
\text { clothes washer, do not pay for hot water }\end{array}$ \\
318 (84.0) & $\begin{array}{l}\text { Source: Simplified Equation } \\
\text { one infant, two school age children, adult at home, } \\
\text { dishwasher, no clothes washer, do not pay for hot } \\
\text { water }\end{array}$ \\
\hline
\end{tabular}




\section{LIMITATIONS AND FUTURE WORK}

The studies from which we obtained data for development of the four additional variables in the expanded model used a variety of methods, samples, locations, and years. From a strict statistical viewpoint, the manner in which we combined data from these studies is not completely justifiable. However, we believe that the significance of our corrections outweighs the inaccuracies created by inconsistencies among the studies. Obviously additional rigorous field studies would be very helpful in this area.

The variation of hot water use between demographically identical households has not been addressed here. Occupant behavior can significantly influence hot water use. Examples are the fraction of hot, warm, and cold wash cycles used in clothes washers; the amount of hot water used for hand washing dishes; or the number, length, and temperature of showers. These factors are not addressed at all in this model.

The EPRI model was developed based upon data collected before 1980. Since then, energyefficiency and water-efficiency standards have changed, as has residential use of hot water consuming appliances. It is commonly assumed that less hot water is now used for showers and clothes washers, but, so far, no reliable studies have quantified this assumption. In our expansion of the EPRI model, no attempt was made to account for hot water end-use changes over the past 15 years. Further research must be done to develop sufficient data for such an analysis.

Some analyses based on whole-house gas and electric utility bills suggest that households with electric water heaters use less hot water than comparable households with gas-fired water heaters (Latta 1995). Because electric water heaters typically have lower recovery rates, it seems plausible that occupants of households with electric water heaters would learn to limit hot water use to avoid running out of hot water. In addition, the higher cost of heating a given amount of water with electricity, compared with natural gas, may be an incentive for people with electric water heaters to reduce their hot water usage. A Battelle comparison of metered water heater studies, however, found no difference in hot water use between households with electric and gas-fired water heaters; a limitation of the Battelle comparison is that the studies of gas-fired water heaters reported gas use rather than hot water use, and Battelle was thus required to do the conversion (Paul 1995 ). The authors of this report are not aware of any recent studies based on metered hot water use in households with gas-fired water heaters. Because of the lack of metered hot water consumption data for households with gas-fired water heaters, we did not attempt to account for possible differences of hot water use associated with different types of water heaters. Future studies of hot water use should distinguish among the various usage characteristics associated with electric, gas-fired, and possibly oil-fired, water heaters. 


\section{CONCLUSION}

This report presents a detailed model of residential hot water use patterns in individual households. The model improves upon an existing model by including the effects of four conditions that were previously unaccounted for: the absence of a clothes washer; the absence of a dishwasher; a household consisting of seniors only; and a household that does not pay for its own hot water use. Although these four conditions can significantly affect residential hot water use, and have been noted in other studies, this is the first time that they have been incorporated into a detailed model. The model allows detailed evaluation of the impact of potential efficiency standards for water heaters and other market transformation policies.

Many of the hot water metering studies this report is based on were carried out 10 to 15 years ago. Further research should be done to account for changes in energy and water efficiency standards for hot water using appliances and for changes in consumer habits in the intervening years. In addition, most metering studies to date have focused on electric water heaters; future studies should also include gas-fired, and possibly oil-fired, water heaters. 


\section{REFERENCES}

. 1994. “The Saturation Picture.” Appliance. September. p. 70.

Becker, B.R. and K.E. Stogsdill. 1990 A domestic hot water use database: Identifying the factors that influence domestic hot water use can help develop more efficient systems. ASHRAE Journal, September. p. $21-25$

Bureau of the Census, 1991, Census of Population and Housing: Summary Tape File 3A, U.S. Department of Commerce, August

Ciz, J.B. 1986. Performance of Domestic Hot Water Systems in Five Apartment Buildings (Part I -- Installation and Commissioning). Ontario Hydro Research Division. RP:86-77-K. July.

Energy Information Administration (EIA). 1993. Household Energy Consumption and Expenditures 1990. U.S. Department of Energy. February.

Energy Information Administration (EIA). 1995. Housing Characteristics 1993. U.S. Department of Energy. June.

Erikson, John T. 1995. Personal Communication Regarding Laundry \& Dish Habits \& Practices to James McMahon of LBNL. Ivorydale Technical Center, Procter \& Gamble. May.

Goldner, Fredric S. 1994. Energy Use and Domestic Hot Water Consumption, Final Report, Phase 1. Prepared for The New York State Energy Research and Development Authority. Brooklyn, NY. November.

Jacobson, Ronald L. 1989. Comment Regarding Proposed Energy Conservation Standards for Three Types of Consumer Products (Dishwashers, Clothes Washers, and Dryers) (Docket No. CE-RM-88-101). Ivorydale Technical Center, Procter \& Gamble. October.

Jacobson, Ronald L. 1994. Personal Communication Regarding Temperature Use Factors and Machine Laundering Frequency for Washing Machines to Mark LaFrance, U.S. DOE. Ivorydale Technical Center, Procter \& Gamble. September.

Jacobson, Ronald L. 1995. Comment Regarding Three Cleaning Products Rulemaking (Docket No. EE-RM-94-403) to U.S. DOE. Ivorydale Technical Center, Procter \& Gamble. January.

Ladd, G.O. and J.L. Harrison. Gilbert Associates, Inc. 1985. Electric Water Heating for Single-Family Residences: Group Load Research and Analysis. Prepared for Electric Power Research Institute. EPRI EA-4006. Palo Alto, CA. May.

Latta, R. 1995. An Analysis of Energy Used to Heat Water Based Upon Consumer Utility Bills, Seminar 06, Are Residential Water Heating Consumption Calculation Methods Out of Step with the Real World? ASHRAE Annual Meeting, Technical Conference. June

Merrigan, T.J. 1988 Residential Hot Water Use in Florida and North Carolina. ASHRAE Transactions, Vol. 94, Part 1.

Milligan, N.H. 1987. Performance of Domestic Hot Water Systems in Five Apartment Buildings (Part II -- Analysis and Results). Ontario Hydro Research Division. RP:87-53-K. April.

Paul, D.D, B.E. Ide, and P.A. Hartford. Battelle Memorial Institute. 1994. Residential Hot Water Usage: A Review of Published Metered Studies. Prepared for Gas Research Institute. Chicago, IL. GRI-94/0442. December.

Perlman, M. and B. E. Mills, 1985. Development of Residential Hot Water Use Patterns. ASHRAE Transactions, Vol. 91, Part 2. Atlanta, GA. 
Perlman, M. and N.H. Milligan, 1988. Hot Water and Energy Use in Apartment Buildings. ASHRAE Transactions. Vol. 94, Part 1. Atlanta, GA.

Sanik, Margaret Mietus. 1990. Hand Versus Machine Dishwashing. International Appliance Technical Conference Proceedings. Columbus, Ohio. May.

Sanik, Margaret Mietus. 1990. Use of Inputs in Hand vs. Machine Dishwashing. Association of Home Equipment Educators, National Technical Conference Proceedings. Minneapolis, MN. October.

Thrasher, W.H., D.W. DeWerth, and B.R. Becker. 1990 "Residential Buildings: Single and Multi-Family.” Comparison of Collected and Compiled Existing Data on Service Hot Water Use Patterns in Residential and Commercial Establishments: Phase I Final Report. Prepared for ASHRAE. Research Project No. 600. Atlanta, GA. August. p. 41-70.

Vine, E., R. Diamond, and R. Szydlowski. 1986. "Domestic Hot Water Consumption in Four Low-Income Apartment Buildings.” Energy Vol. 12, No. 6. June. 


\section{APPENDIX A: EXPANDED MODEL EQUATIONS}

The 16 equations below predict hot water consumption patterns for individual households on weekdays and weekends. They need to be done four times with different values of seasonal dummy variables to capture seasonal variations, which are presented as follows:

(1) Spring $=1$ and Summer $=0$ and Fall $=0$ and Winter $=0$;

(2) Spring $=0$ and Summer $=1$ and Fall $=0$ and Winter $=0$;

(3) Spring $=0$ and Summer $=0$ and Fall $=1$ and Winter $=0$;

(4) Spring $=0$ and Summer $=0$ and Fall $=0$ and Winter $=1$;

The model is presented in a matrix (two-dimensional array). Columns represent all variables in the models and rows represent 16 equations for all draw schedules (eight time periods on weekdays and weekends). Variables derived from the linear regression in the EPRI study occupy the first 13 columns. The newly derived variables added to the expanded model are in the last four columns. Explanation of the variables is given in the body of this report. 
WEEKDAY (SI units)

\begin{tabular}{|c|c|c|c|c|c|c|c|c|c|c|c|c|c|c|c|c|c|c|}
\hline \multicolumn{15}{|c|}{ EPRI } & \multicolumn{4}{|c|}{ EXPANDED } \\
\hline hour & $\mathrm{a} 0$ & a1 & a2 & a3 & a4 & a5 & a6 & a7 & a8 & a9 & a10 & a11 & a12 & a13 & no_dw & no_cw & senior & no_pay \\
\hline & (const) & (per) & (age1) & (age2) & (age3) & (therm) & $(\operatorname{tank})$ & (wtmp) & (atmp) & (athome) & (spring) & (summer) & (fall) & (winter) & (1) & (3) & (5) & (6) \\
\hline 11-6 & 0 & \begin{tabular}{|l|l|}
0.6163 \\
\end{tabular} & 0 & 0 & 0 & 0 & -0.0017 & 0 & 0 & 0 & 0 & 0 & 0 & 0.5523 & 0 & 0 & \begin{tabular}{|l|}
0.379 \\
\end{tabular} & 1.3625 \\
\hline 6-8 & 2.0956 & 0 & 0 & 3.4830 & \begin{tabular}{|l|}
7.9861 \\
\end{tabular} & 0 & 0.0269 & \begin{tabular}{|l}
-0.5424 \\
\end{tabular} & 0.6603 & \begin{tabular}{|l|}
-3.6609 \\
\end{tabular} & 0 & \begin{tabular}{|l|}
-13.6010 \\
\end{tabular} & 0 & 0 & 0 & 0 & \begin{tabular}{|l|l|}
0.379 \\
\end{tabular} & 1.3625 \\
\hline 8-11 & 0 & 0 & 1.0853 & 1.5331 & 2.4972 & 0 & 0 & 0 & 0 & 9.0418 & 0 & 0 & -1.6353 & 2.1403 & 0 & 0 & 0.379 & 1.3625 \\
\hline 11-1 & -0.3876 & 0 & 0.9668 & 1.0849 & 2.0956 & \begin{tabular}{|l|} 
\\
\end{tabular} & 0 & 0 & 0 & 6.1986 & 0 & 0 & -1.6834 & 1.5187 & 0 & 0 & \begin{tabular}{|l|l|} 
& 0.379 \\
\end{tabular} & \begin{tabular}{|l|l|}
1.3625 \\
\end{tabular} \\
\hline $1-5$ & -0.2907 & 0 & 1.9790 & 1.2000 & 2.3072 & \begin{tabular}{|l|}
-0.0906 \\
\end{tabular} & 0.0083 & 0 & 0.0743 & 4.0228 & 0 & 0 & 0 & 2.5854 & 0 & 0 & \begin{tabular}{|l|}
0.379 \\
\end{tabular} & 1.3625 \\
\hline 5-7 & 0.7753 & 0 & 1.5679 & 2.0415 & 3.6018 & 0 & 0 & -0.3134 & 0.3570 & 5.3492 & 0 & -3.6855 & 0 & 3.6560 & (2) & 0 & 0.379 & 1.3625 \\
\hline 7-9 & 4.4577 & 0 & 2.7456 & 4.4092 & 3.3455 & -0.1015 & 0.0187 & 0 & 0.3523 & 0 & 0 & -8.0527 & \begin{tabular}{|l|} 
\\
\end{tabular} & 0 & (2) & (4) & 0.379 & 1.3625 \\
\hline 9-11 & 4.2881 & 0 & 1.4434 & 3.4394 & 2.5135 & -0.0436 & 0 & 0 & 0.2848 & -2.4166 & 0 & -3.3773 & \begin{tabular}{|l|} 
\\
\end{tabular} & 0 & 0 & 0 & \begin{tabular}{|l|l|} 
& 0.379 \\
\end{tabular} & \begin{tabular}{|l}
1.3625 \\
\end{tabular} \\
\hline
\end{tabular}

\section{WEEKEND (SI units)}

\begin{tabular}{|c|c|c|c|c|c|c|c|c|c|c|c|c|c|c|c|c|c|c|}
\hline \multicolumn{15}{|c|}{ EPRI } & \multicolumn{3}{|c|}{ EXPANDED } & \multirow[b]{2}{*}{ no_pa } \\
\hline hour & $\mathrm{a} 0$ & $\mathrm{a} 1$ & $\mathrm{a} 2$ & a3 & $\mathrm{a} 4$ & a5 & $\mathrm{a} 6$ & a7 & \begin{tabular}{|l|}
$\mathrm{a} 8$ \\
\end{tabular} & \begin{tabular}{|l|}
$\mathrm{a} 9$ \\
\end{tabular} & a10 & a11 & a12 & a13 & no_dw & no_cw & senior & \\
\hline & (const) & (per) & \begin{tabular}{|l|} 
(age1) \\
\end{tabular} & (age2) & (age3) & (therm) & $(\operatorname{tank})$ & (wtmp) & (atmp) & (athome) & \begin{tabular}{|l} 
(spring) \\
\end{tabular} & (summer) & (fall) & (winter) & (1) & (3) & (5) & (6) \\
\hline $11-6$ & 0 & 0.3036 & 0 & 0 & 0 & 0 & -0.0017 & 0 & 0 & 0 & 0.3433 & 0.6341 & 0 & 0.6420 & 0 & 0 & 0.379 & 1.3625 \\
\hline $6-8$ & 3.8036 & 0 & 0 & 1.1515 & 1.3389 & 0 & 0.0269 & 0 & 0.2140 & 0 & 0.0000 & -5.9393 & -2.4806 & 0.0000 & 0 & 0 & 0.379 & 1.3625 \\
\hline $8-11$ & 0 & 0 & 1.3045 & 2.7796 & 5.6808 & 0 & 0 & 0 & 0 & 0 & 4.7598 & 0 & 0 & 5.1164 & 0 & 0 & 0.379 & 1.3625 \\
\hline $11-1$ & 2.5923 & 0 & 0.9009 & 2.0070 & 5.4181 & -0.1833 & 0 & 0 & 0.3291 & 0 & 0 & -4.7840 & 0 & 5.6039 & 0 & 0 & 0.379 & 1.3625 \\
\hline $1-5$ & 1.8170 & 0 & 1.7303 & 1.7201 & 3.8043 & -0.1445 & 0.0083 & 0 & 0.2467 & 0 & 0 & -3.5602 & 0 & 4.4501 & 0 & 0 & 0.379 & 1.3625 \\
\hline $5-7$ & 3.1616 & 0 & 2.1596 & 2.9693 & 3.8607 & \begin{tabular}{|l|}
-0.1806 \\
\end{tabular} & 0 & 0 & \begin{tabular}{|l|}
0.3584 \\
\end{tabular} & 0 & 0 & \begin{tabular}{|l|}
-5.6168 \\
\end{tabular} & 0 & 6.2020 & (2) & 0 & \begin{tabular}{|l|l}
0.379 \\
\end{tabular} & 1.3625 \\
\hline $7-9$ & 3.5007 & 0 & \begin{tabular}{|l|}
1.2038 \\
\end{tabular} & 4.9574 & 2.3144 & 0 & 0.0187 & 0 & 0.1969 & 0 & 3.1275 & \begin{tabular}{|l|}
-3.6961 \\
\end{tabular} & 0 & 0 & (2) & (4) & 0.379 & 1.3625 \\
\hline $9-11$ & 0 & 0 & \begin{tabular}{|l|}
1.8965 \\
\end{tabular} & 3.0862 & 2.5695 & 0 & 0 & 0 & 0 & 0 & 0 & 0 & -1.4339 & 0 & 0 & 0 & \begin{tabular}{|l|l|}
0.379 \\
\end{tabular} & 1.3625 \\
\hline
\end{tabular}
(1) no_dw is only applied to households without dishwashers.
(3) no_cw is only applied to households without clothes washers.
(5) senior has a value of 1 in households that are not seniors only.

(2) see equation (12) in text

(4) see equation (8) in text.

(6) no_pay has a value of 1 in households that pay for the hot water they use. 
WEEKDAY (I-P units)

\begin{tabular}{|c|c|c|c|c|c|c|c|c|c|c|c|c|c|c|c|c|c|}
\hline \multicolumn{14}{|c|}{ EPRI } & \multicolumn{4}{|c|}{ EXPANDED } \\
\hline hour & $a_{1}$ & $a_{2}$ & $a_{3}$ & $a_{4}$ & $a_{5}$ & $a_{6}$ & $\mathrm{a}_{7}$ & $a_{8}$ & $a_{9}$ & $a_{10}$ & $a_{11}$ & $a_{12}$ & $a_{13}$ & no_dw & no_cw & senior & no_pay \\
\hline & (per) & (age1) & (age2) & (age3) & (therm) & (tank) & (wtmp) & (atmp) & (athome) & (spring) & (summer) & (fall) & (winter) & (1) & (3) & (5) & (6) \\
\hline $11-6$ & 0.1628 & 0 & 0 & 0 & 0 & -.0017 & 0 & 0 & 0 & 0 & 0 & 0 & .1459 & 0 & 0 & .3790 & 1.3625 \\
\hline $6-8$ & 0 & 0 & .9201 & 2.1097 & 0 & .0269 & -.0796 & .0969 & $\mid-.9671$ & 0 & -3.593 & 0 & 0 & 0 & 0 & .3790 & 1.3625 \\
\hline $8-11$ & 0 & .2867 & .4050 & .6597 & 0 & 0 & 0 & 0 & 2.3886 & 0 & 0 & -.432 & .5654 & 0 & 0 & .3790 & 1.3625 \\
\hline $11-1$ & 0 & .2554 & .2866 & .5536 & -.0032 & 0 & 0 & 0 & 1.6375 & 0 & 0 & -.4447 & .4012 & 0 & 0 & .3790 & 1.3625 \\
\hline $1-5$ & 0 & .5228 & .3170 & .6095 & -.0133 & .0083 & 0 & .0109 & 1.0627 & 0 & 0 & 0 & .683 & 0 & 0 & .3790 & 1.3625 \\
\hline 5-7 & 0 & .4142 & .5393 & .9515 & 0 & 0 & \begin{tabular}{|l|}
.0460 \\
\end{tabular} & .0524 & 1.4131 & 0 & -.9736 & 0 & .9658 & (2) & 0 & .3790 & 1.3625 \\
\hline 7-9 & 0 & .7253 & 1.1648 & .8838 & -.0149 & .0187 & 0 & .0517 & 0 & 0 & -2.1273 & -.8588 & 0 & $(2)$ & (4) & .3790 & 1.3625 \\
\hline $9-11$ & 0 & .3813 & .9086 & .6640 & -.0064 & 0 & 0 & .0418 & -.6384 & 0 & -.8922 & -.9381 & 0 & 0 & 0 & .3790 & 1.3625 \\
\hline
\end{tabular}

WEEKEND DAY (I-P units)

\begin{tabular}{|c|c|c|c|c|c|c|c|c|c|c|c|c|c|c|c|c|c|}
\hline \multicolumn{14}{|c|}{ EPRI } & \multicolumn{4}{|c|}{ EXPANDED } \\
\hline hour & $a_{1}$ & $\mathrm{a}_{2}$ & $a_{3}$ & $a_{4}$ & $a_{5}$ & $a_{6}$ & $\mathrm{a}_{7}$ & $a_{8}$ & $a_{9}$ & $a_{10}$ & $a_{11}$ & $a_{12}$ & $a_{13}$ & no_dw & no_cw & senior & \begin{tabular}{|l|} 
no_pay \\
\end{tabular} \\
\hline & (per) & (age1) & (age2) & (age3) & (therm) & $(\operatorname{tank})$ & (wtmp) & (atmp) & (athome) & (spring) & (summer) & (fall) & (winter) & (1) & (3) & (5) & (6) \\
\hline \begin{tabular}{|l|}
$11-6$ \\
\end{tabular} & \begin{tabular}{|l|}
.0802 \\
\end{tabular} & 0 & 0 & 0 & 0 & 0 & 0 & 0 & 0 & \begin{tabular}{|l|}
.0907 \\
\end{tabular} & \begin{tabular}{|l|}
.1675 \\
\end{tabular} & 0 & \begin{tabular}{|l|}
.1696 \\
\end{tabular} & 0 & 0 & .3790 & 1.3625 \\
\hline \begin{tabular}{|l|}
$6-8$ \\
\end{tabular} & 0 & 0 & .3042 & \begin{tabular}{|l|}
.3537 \\
\end{tabular} & 0 & 0 & 0 & .0314 & 0 & 0 & -1.569 & \begin{tabular}{|l|}
-.6553 \\
\end{tabular} & 0 & 0 & 0 & .3970 & 1.3625 \\
\hline 8-11 & 0 & .3446 & .7343 & \begin{tabular}{|l|}
1.5007 \\
\end{tabular} & 0 & 0 & 0 & 0 & 0 & \begin{tabular}{|l|}
1.2574 \\
\end{tabular} & 0 & 0 & 1.3516 & 0 & (4) & .3970 & 1.3625 \\
\hline \begin{tabular}{|l|}
$11-1$ \\
\end{tabular} & 0 & .238 & .5302 & \begin{tabular}{|l|}
1.4313 \\
\end{tabular} & -.0269 & \begin{tabular}{|l|l|}
.0225 \\
\end{tabular} & 0 & .0483 & 0 & 0 & -1.2638 & 0 & 1.4804 & 0 & 0 & .3970 & \begin{tabular}{|l|}
1.3625 \\
\end{tabular} \\
\hline $1-5$ & 0 & .4571 & \begin{tabular}{|l|l|}
.4544 \\
\end{tabular} & \begin{tabular}{|l|}
1.005 \\
\end{tabular} & \begin{tabular}{|l|}
-.0212 \\
\end{tabular} & .022 & 0 & .0362 & 0 & 0 & -.9405 & 0 & 1.1756 & 0 & 0 & .3970 & 1.3625 \\
\hline $5-7$ & 0 & $\begin{array}{l}.5705 \\
\end{array}$ & .7844 & 1.0199 & $\begin{array}{l}-.0265 \\
\end{array}$ & .036 & 0 & .0526 & 0 & 0 & -1.4838 & 0 & 1.6384 & (2) & 0 & .3970 & 1.3625 \\
\hline $7-9$ & 0 & .318 & 1.3096 & .6114 & 0 & 0 & 0 & .0289 & 0 & .8262 & -.9764 & 0 & 0 & (2) & 0 & .3970 & 1.3625 \\
\hline 9-11 & 0 & .501 & .8153 & \begin{tabular}{|l|}
.6788 \\
\end{tabular} & 0 & \begin{tabular}{|l|}
.0083 \\
\end{tabular} & 0 & 0 & 0 & 0 & 0 & \begin{tabular}{|l|}
-.3788 \\
\end{tabular} & 0 & 0 & 0 & .3970 & 1.3625 \\
\hline
\end{tabular}

(1) no $d w$ is only applied to households without dishwashers.

(3) no_cw is only applied to households without clothes washers.

(5) senior has a value of 1 in households that are not seniors only.
(2) see equation (12) in text.

(4) see equation (8) in text

(6) no_pay has a value of 1 in households that pay for the hot water they use. 